\title{
The 50-Year War on Cancer Revisited: Should We Continue to Fight the Enemy Within?
}

\author{
Young-Joon Surh \\ College of Pharmacy, Department of Molecular Medicine and Biopharmaceutical Sciences, Graduate School of \\ Convergence Science and Technology, Cancer Research Institute, Seoul National University, Seoul, Korea
}

\section{PROLOGUE}

This year marks the 50th anniversary of the "War on Cancer" declared by Richard Nixon, a former President of the United States of America. By signing into law the National Cancer Act on December 23, 1971, Nixon hoped this action to be the landmark legislation taken by his administration. Nixon apparently had confidence that cancer would be conquered in 5 years. This was indeed a surprisingly wonderful X-mas present to the nation.

The act represented an important turning point in cancer research as well as treatment. As a result of enthusiasm in US Congress for eradicating cancer, there was a remarkable increase in the budget of National Cancer Institute ( $\mathrm{NCl}$ ) of which substantial portions were spent in supporting the basic research to reduce the incidence, morbidity and mortality from cancer. According to Vincent Devita who served as Director of US NCI from July 9, 1980 to September 1, 1988 and later directed Yale Cancer Center, the results have been explosive, leading to the revolution in molecular biology of cancer [1].

Though the 'War on Cancer' was officially declared in 1971 , it actually had begun in about two years ago. On December 9, 1969, full-page advertisements were appeared in Washington Post and New York Times, entitled: "Mr. Nixon: you can cure cancer". These ads were planned and initiated by the Citizens' Committee for the Conquest of Cancer in which Marry Lasker played a prominent role. She was the widow of Chicago advertising executive Albert Lasker, and was a socialite, a philanthropist, and an activist. As a longtime supporter of public health causes, including national health insurance, Mrs. Lasker used her influential power and political network to rally support for cancer research [2].

The ad was effective. President Nixon heard the voice of the people who expressed their concern and wish to cure cancer. In his famous State of the Union address in January 1971 , Nixon made a special request for an extra $\$ 100$ million (equivalent approximately to $\$ 690,000,000$ in 2021) to launch an intensive campaign to find a cure for cancer, and also for whatever additional funds later, if necessary, that can effectively be used. Marry Lasker, together with other individuals including policymakers and investment bankers, developed the framework of the National Cancer Act, which the President endorsed by the end of that year [3].

\section{TRIUMPHS AND DEFEATS}

The Washington Post advertisement appeared less than five months after American astronauts landed on the moon on July 20, 1969, for the first time in human history. In his January 1971 State of the Union address, President Nixon said with confidence: "The time has come in America when the same kind of concentrated effort that split the atom and took man to the moon should be turned toward conquering this dread disease". "Let us make a total national commitment to achieve this goal". However, curing cancer would be much harder than putting a man on the moon. It is different from an engineering project for which unifying fundamental physical theory had been well understood. With cancer, things are much more complicated, and its conquest requires an enormous scientific challenge.

Though Nixon envisioned conquest of cancer by the nation's bicentennial anniversary which was 1976, this promise turned out hopelessly over-optimistic. Yet from the beginning, the War on Cancer was objected by many leading scientists and experts. The Nobel-winning biologist, James Watson criticized at a symposium held in MIT in 1975 that the American public had been sold a "nasty bill of goods about cancer". 
Professor Sol Spiegelman, Director of the Institute of Cancer Research at Columbia University, said "an all-out effort at this time [to conquer cancer] would be like trying to land a man on the moon without knowing Newton's laws of gravity" [2,3]. When President Nixon signed the National Cancer Act on December 23, 1971, the Vietnam War was still ongoing. Mary Lasker and her Citizens' Committee for the Conquest of Cancer ran a skilful campaign during 1969 to 1971, by comparing the number of cancer deaths with American troop losses that of American soldiers lost in the unpopular Vietnam War [3] that was ended in few years in spectacular defeat. Donald Kennedy who headed US FDA and the Stanford University later described the war on cancer as "A Medical Vietnam" [4].

So, despite immense advances in basic scientific knowledge about cancer as well as the marked increase in resources, the war on cancer went poorly. In 1986, Bailar and Smith concluded that "some 35 years of intense effort focused largely on improving treatment must be judged a qualified failure" [5]. Eleven years later, Bailar and Gornik [6] published an updated version, titled "Cancer Undefeated" and addressed that with 12 more years of data and experience, there was little reason to change their earlier conclusion [7].

After publication of the above paper, there were a lot of critiques and scholarly debates. It has been argued that there have been incredible advances in the battle against cancer in recent decades. Although the cancer incidence has increased by and large, so has the cancer survival. This is the good news: now more people are surviving cancer than are dying of the disease. Moreover, the age-adjusted overall cancer death rate (mortality) in the United States has declined steadily since the early 1990 s $[8,9]$. In this context, optimism has replaced pessimism in the war on cancer [7].

Of the numerous decisive victories made since the US federal government launched the battle against cancer in 1971, perhaps the greatest advance is the explosion in scientific knowledge about cancer. The revolution in basic molecular and cell biology has led to many fascinating new discoveries [10]. No one would have expected that within ten years of Nixon signing the National Cancer Act, the first cancer-causing gene (c-Src) lurking in our own cells could be discovered. The majority of the $\mathrm{NCl}$ budget was invested in support for basic research programs, and these investments led to the development of the targeted therapies and personalized (precision) medicine [9].

\section{TIME TO RETHINK ABOUT THE WAR METAPHOR}

Over the 50 years since President Nixon's declaration of the 'War on Cancer' in 1971, cancer has become inseparable from the rhetoric of warfare. As we commemorate the 50th anniversary of the National Cancer Act, it is time to think more seriously about whether we are talking about cancer in the right way. War, in general, has a winner and a loser. The use of war as a metaphor to describe cancer treatment may mislead the patients to believe that they can defeat cancer with a single 'magic bullet' cure. For some cancer patients, their families, and supporters, the use of military language may motivate them by embracing a fighting spirit. However, framing cancer as an enemy and the process of its treatment as war, in general, could do more harm than good.

Cancer destroys not only patients' physical health, but also their own mental health at the same time. Psychologists say use of military clichés can be unhelpful and even can make people more fearful and fatalistic, especially for terminal cancer patients who have no effective therapeutic options. Some cancer patients feel guilty and disempowered if treatment doesn't go well or if their cancer comes back despite treatment [11]. When someone dies from cancer, is it because they didn't fight hard enough? If they choose to focus on their quality of life rather than pursue cure-directed therapy, are they waving the white flag? [11]. Therefore, the outcome of the war on cancer may not be summarized in the same way as for warfare, namely 'fought' (battle), 'won' (beat) or 'lost' (defeat). It is not appropriate to declare war on a disease like cancer [3]. If we continue to use the such violence metaphors of victory and defeat, the combat against cancer will remain defeated as a whole because millions of people world-wide are diagnosed with cancer each year, and many of these patients die, and this trends is unlikely to change for decades to come [3].

\section{CONQUEST FOR CANCER-MISSION IMPOSSIBLE?}

Like warfare, the primary focus in cancer therapy has been, and still is, on how to more efficiently kill the as many undesired cells as possible under the assumption that this will cure the disease $[12,13]$. The battlefield analogies may result in over-diagnosis as well as over-treatment of some malignancies though there is a paucity of data demonstrating that maximum tolerated doses allow longer survival than minimum effective doses [14].

Despite all the very expensive and toxic radical "weapons", the enemies are not totally destroyed. On the contrary, this causes "collateral damage" accompanying unnecessary toxicities in normal cells and inevitably reduces the patient's the quality of life [14]. Even for recently developed "magic bullets" intended to selectively kill the cancer cells in the tumor microenvironment without much influencing the surrounding stromal cells, they fail to eradicate the residual tumor which typically relapses after a year or less. And when the tumor recurs, it is more malignant and uncontrollable than before [12]. Thus, more efficient killing of undesired cells like terrorists may not always be better, a lesson we cancer warriors have yet to learn [12].

The dominant cancer metaphor describes tumor as invading army, a barbarian horde attacking from outside city walls. 
But now, a new way of thinking about the disease has been proposed: likening cancer cells to local residents gone bad who slowly exploit the environment around them for their own gain. "Cancers are not outside the body," "They come from within us" [13]. Lessons learned in dealing with exotic species, combined with recent mathematical models of the evolutionary dynamics of tumours, indicate that eradicating most disseminated cancers (like terrorist) may be impossible. And, more importantly, trying to do so could make the problem worse [13].

\section{LIVING WITH CANCER}

Cancer is derived from a healthy cell, a disease that lives within us, and hence better to manage, not to fight. Perhaps, rather than speaking of cancer in militaristic terms, it's better to communicate that we are "living with cancer" for as long and as well as we can. So when someone with a cancer dies, let's not say that he/she has lost anything, but rather that the person has died after living with the disease for a while.

There is debate about whether we should be aiming for curing cancer. Perhaps, it is more realistic to treat cancer as one of chronic, manageable diseases. So, long-term treatment that will allow cancer patients to live with their cancer while maintaining the quality of life may be an acceptable option. This should consider the somewhat iconoclastic idea of managing tumor growth rather than eliminating it altogether [15].

In order to manage tumor, comprehensive understanding of the more sophisticated natural history of cancer is needed. Cancer cells are phenotypically heterogeneous and plastic, not static: they adapt, evolve and become resistant to treatment [12]. In consideration of the evolution of concepts on the nature of cancer, a rethinking of the tumor-host relationship has occurred. Early ideas about their antagonism and the lifeand-death struggle have been exchanged for the realization of their paradoxical "love, not war" relationship. Indeed, without the support of many normal cells in the stroma of tumor microenvironment, the cancer cell cannot arise and spread. This gives grounds for considering "carcinogenesis as collective rather than individual 'guilt,' and puts the blame on the whole cellular community rather than on a single (entity of tumor)" [16].

\section{MORE PREVENTION}

The war on cancer that has been fighting many of the wrong battles with wrong weapons is largely futile. The return on investment is not impressive. There has been too much emphasis on the "cure for cancer" over prevention during the past 50 year War on Cancer. The heterogeneity evolutionary dynamics of the tumors hamper the eradication of this dreaded disease.

Battles rarely involve prevention. The war metaphors affect inferences about prevention as well as treatment, as it generates pessimistic or fatalistic beliefs. By portraying cancer as a formidable enemy to actively combat, we are less likely to maintain healthy lifestyle or enact behaviors to prevent cancer [11]. As a consequence, therapeutic attacks have been prioritized over strategies to prevent the cancer. We should stop using such misguided war game analogies of winning and losing, and had better focus on prevention to make longterm progress against this elusive enemy [3].

Unfortunately, however, the means to prevent most cancers have not yet been elucidated, adequately tested, and shown to be effective and feasible. The most promising approach to the control of cancer is a national commitment to prevention, with a concomitant rebalancing of the focus and funding of research [6]. In comparison to the resources assigned to the treatment of advanced cancer, inadequate effort has been dedicated to preventing the multi-step carcinogenesis, especially in the early stages [10].

\section{Primary prevention}

The major risk factors for cancer are well identified. It has been considered that primary prevention, a way to fight cancer on the basis of present knowledge about identifiable risk factors, is cost effective [17]. If complemented by earlier detection and more effective treatment, primary cancer prevention would progress markedly. The benefits of prevention take time to manifest, which needs leadership and vision from policy makers and educational efforts to bear fruits [17].

Though we can substantially reduce the risk of cancer by eliminating the carcinogenic factors from our environment or at least minimizing exposure to them, this normally requires drastic changes in our life style or behavior which are difficult to practice. Moreover, for those individuals with genetic predisposition to a particular type of malignancy; for instance, breast cancer and colorectal cancer due to mutations in tumor suppressor genes, BRCA and $A P C$, respectively, such primary prevention may not be effective. For them, more active strategies are needed.

\section{Chemoprevention}

The concept of more active cancer interception involves blockade of premalignant lesion and halting transformed cells from becoming malignant cancers [18]. This is a fundamental basis of 'chemoprevention', a term coined by in 1970's by Michael Sporn [19].

So far numerous substances have been shown to possess promising cancer chemopreventive potential. These include edible phytochemicals [20] and synthetic pharmaceuticals, such as anti-inflammatory drugs [21]. While the majority of these compounds or their mixtures have been tested in cultured cells or laboratory animals, some have been subjected to clinical trials. However, in many cases, there have been side effects observed after long-term administration of some chemopreventive agents for the purpose of chemopreven- 
tion. For instance, coxib drugs (e.g., celecoxib and rofecoxib), selectively targeting cyclooxygenase-2 (COX-2) reduced the formation of polyps, and potentially colorectal cancer, but their promise for use as chemopreventive formulations was halted abruptly due to the cardiovascular complications $[22,23]$. Nonetheless, it this is just a 'risk and benefit issue' $[18,23]$ : if the a given chemopreventive provides more benefit over harm, it may be considered for use; if the same agent has more harm than benefit or exerts an unusual serious side effects though frequency is relatively low, it is banned. We had the same controversy with the recent COVID-19 vaccination. It will be worthwhile searching for/developing safer and effective chemopreventive agents, and also to consider concomitant use of multiple existing chemopreventive agents ("combination chemoprevention") [24].

Clinical chemoprevention is still in its infancy, with its unique set of problems and need for further support. Unfortunately, a disproportionately low level of funding, both within the academic research establishment as well as in the pharmaceutical industry, is still being given to chemoprevention research, as opposed to efforts directed toward the treatment of cancer [10]. Cancer (chemo)prevention should be actively proposed even to healthy individuals, and not just to individuals with high cancer risk [18]. On the basis of the evaluation of cancer risk, personalized approaches for cancer prevention and preventive interception have been suggested. Investment into translational research to bring these approaches into public health policies and in the clinic is urgently needed [18].

\section{EPILOGUE}

Fifty years ago, a metaphor was posed that cancer was such an insidious adversary that a declaration of war on the disease was justified [25]. Another metaphor concerns magic bullets targeting one of the hallmarks of cancer, which is intended to selectively kill cancer cells without much damaging normal cells. Unfortunately, such targeted therapies are generally not curative, because of the adaptive characteristics and evolutionary nature of cancers under attack, conferring the drug resistance [25]. Since the outbreak of COVID-19 pandemic, the media have frequently referred to the "battle" against coronavirus, health care workers as "heroes," and life on the "front lines" of the pandemic. Optimally, however, such war metaphors should be avoided; they may actually do more harm than good as we learned lessons from the battle with cancer [8].

Over the past five decades, there has been tremendous improvement in the treatment of cancer, particularly new targeted therapies including recently developed cancer immunotherapy. Nonetheless, it might be too early to congratulate on victory. The overall mortality statistics (death rates) for most of the common carcinomas is not still optimistic. Obsession with cure of cancer in an advanced stage rather than intervention in the early stage of the disease, and neglect of the need to arrest preneoplastic legions may all have served to make victory elusive [10]. In 2016, Joseph Biden, who was Vice President of US at that time, announced the "Cancer Moonshot" initiative with the full support of President Obama to end cancer. Many in the scientific community felt a twinge of déjà vu of President Nixon's State of the Union speech given in 1971.

In celebrating the 50th year of war on cancer, we need to re-evaluate our triumphs and failures. Cancer is a preventable rather than a treatable disease as Michael Sporn [10] addressed 25 years ago. We do not propose that research on treatment be stopped, but request a substantial realignment of the balance between treatment and prevention. It is now evident that the worldwide cancer research effort tends to be shifted toward prevention. So far government as well as healthcare industry has had little role in these changes. A national commitment to the prevention of cancer, largely replacing reliance on hopes for universal cures, is the way to go [6].

Cancer is now understood to be primarily as a disease that can be managed. However, there are also challenges we have to face in order to make sure that cancer does not become an epidemic like COVID-19 in coming years. The cancer management needs to be tackled in a coordinated way, and in this one team project, 'prevention' shouldn't be a bystander.

\section{ACKNOWLEDGMENTS}

This research was supported by the BK21 FOUR Program (5120200513755) from the National Research Foundation (NRF), Ministry of Science and ICT, Republic of Korea.

\section{CONFLICTS OF INTEREST}

No potential conflicts of interest were disclosed.

\section{ORCID}

Young-Joon Surh, https://orcid.org/0000-0001-8310-1795

\section{REFERENCES}

1. DeVita VT Jr, Rosenberg SA. Two hundred years of cancer research. N Engl J Med 2012;366:2207-14.

2. Fintor L. Cancer program becomes case study in public policy formation. J Natl Cancer Inst 1991;83:1785-9.

3. Coleman MP. War on cancer and the influence of the medicalindustrial complex. J Cancer Policy 2013;1:e31-4.

4. Moss RW. The Cancer Industry. Brooklyn, New York, Equinox Press, 1996.

5. Bailar JC III, Smith EM. Progress against cancer? N Engl J Med 1986;314:1226-32. 
6. Bailar JC III, Gornik HL. Cancer undefeated. N Engl J Med 1997;336:1569-74.

7. Cutler DM. Are we finally winning the war on cancer? J Econ Perspect 2008;22:3-26.

8. Marron JM, Dizon DS, Symington B, Thompson MA, Rosenberg AR. Waging war on war metaphors in cancer and COVID-19. JCO Oncol Pract 2020;16:624-7.

9. DeVita VT Jr. The 'War on Cancer' and its impact. Nat Clin Pract Oncol 2004;1:55.

10. Sporn MB. The war on cancer. Lancet 1996;347:1377-81.

11. Hauser DJ, Schwarz N. The war on prevention II: battle metaphors undermine cancer treatment and prevention and do not increase vigilance. Health Commun 2020;35:1698-704.

12. Huang S. The war on cancer: lessons from the war on terror. Front Oncol 2014;4:293.

13. Gatenby RA. A change of strategy in the war on cancer. Nature 2009;459:508-9.

14. Haines I. The war on cancer: time for a new terminology. Lancet 2014;383:1883.

15. Drake N. Forty years on from Nixon's war, cancer research 'evolves'. Nat Med 2011;17:757.

16. Lichtenstein AV. Strategies of the war on cancer: to kill or to neutralize? Front Oncol 2019;8:667.

17. Vineis P, Wild CP. Global cancer patterns: causes and prevention. Lancet 2014;383:549-57.

18. Albini A, DeCensi A, Cavalli F, Costa A. Cancer prevention and interception: a new era for chemopreventive approaches. Clin Cancer Res 2016;22:4322-7.

19. Theisen C. Chemoprevention: what's in a name? J Natl Cancer Inst 2001;93:743.

20. Surh YJ. Cancer chemoprevention with dietary phytochemicals. Nat Rev Cancer 2003;3:768-80.

21. Wang D, DuBois RN. The role of anti-inflammatory drugs in colorectal cancer. Annu Rev Med 2013;64:131-44.

22. Vanchieri C. Vioxx withdrawal alarms cancer prevention researchers. J Natl Cancer Inst 2004;96:1734-5.

23. Vanchieri C. Researchers plan to continue to study COX-2 inhibitors in cancer treatment and prevention. J Natl Cancer Inst 2005; $97: 552-3$.

24. Sporn MB. Combination chemoprevention of cancer. Nature 1980;287:107-8.

25. Hanahan D. Rethinking the war on cancer. Lancet 2014;383:55863. 